\title{
Mathematical Model for Predicting the Resistivity of an Electroconductive Woven Structure
}

\author{
MAGDALENA TOKARSKA ${ }^{1,2}$ \\ 1.-Department of Architecture of Textiles, Lodz University of Technology, 116 Zeromskiego St., \\ 90-924 Lodz, Poland. 2.—e-mail: magdalena.tokarska@p.lodz.pl
}

Highly conductive woven fabrics (WF) can be used as electronic components. Resistivity is an intrinsic physical property of the conductive textile materials (CTM). The McLachlan model that describes the resistivity of a two-component macroscopic composite (TCMC) subjected to a constant external electric field was proposed to predict the resistivity of fabrics. The volume fraction of voids in material, the voids dimension, and a single morphology parameter were taken into account. The resistivity of a chosen WF was determined based on the model. Verification of the received results was carried out. In the case of four samples, the verification was confirmed by the high level of prediction being in the range of $83-88 \%$. In the case of one sample, the verification was negative $(26 \%)$. This allowed one to pay attention to the influence of compactness and irregularity of the woven structure on results received using the model.

Key words: Two-component composite, electroconductive woven fabric, resistivity, mathematical model

\section{INTRODUCTION}

Resistivity is one of the properties of materials that varies most widely, from $10^{-6} \Omega \mathrm{cm}$ for metals to $10^{18} \Omega \mathrm{cm}$ for electrical insulators. Material is considered electrically conductive if it has a specific resistivity of less than $10^{4} \Omega \mathrm{cm}$. Material is considered to have a metallic conductivity if it has a resistivity of less than $10 \Omega \mathrm{cm} .{ }^{1}$ Electroconductive flat textiles are developed for many applications. Especially, they are electronic components such as sensors and actuators, ${ }^{2}$ electrodes for biosignal measurements, ${ }^{3}$ transmission lines, ${ }^{4}$ and antennas. ${ }^{5}$

There are many technologies that can allow one to get highly conductive textile materials (CTM). ${ }^{2,6}$ Conductivity of fabrics can be enabled during manufacturing. In this case, conductive fibers and yarns are used. The conductivity can also be enabled after manufacturing. In this case, conductive yarns are used during sewing, embroidering, or weaving. ${ }^{7,8}$ Moreover, conductive fabrics can be enabled using coating techniques such as printing,

(Received September 27, 2016; accepted November 24, 2016; published online January 5, 2017)

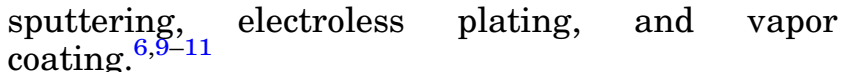

Resistivity is an intrinsic physical property of the CTM. Electroconductive properties of woven and knitted fabrics are modeled using the equivalent resistance schemes in particular. ${ }^{12-16}$ The fabric is seen from an electrical point of view as an electrical circuit composed of connected resistors and a battery. Yarns are ideal resistors of known resistance. The simulated structure is regular. As opposed to the presented models, the model that takes into account an actual structure of woven fabrics (WF) is proposed. It is assumed that the WF are composites that consist of two constituents: conductive and dielectric materials. Yarns are highly conductive textile materials. Yarns create a system of empty spaces and voids filled with air. Therefore, voids are dielectrics and have a size relatively small compared to the characteristic dimensions of WF. Percolation and Bruggeman's effective media theories are used to predict the electrical conductivity of components and combine most aspects of both percolation and effective media theories. ${ }^{17}$ McLach$\operatorname{lan}^{18,19}$ proposed an equation to describe the 
resistivity of a two-component macroscopic composite (TCMC) subjected to a constant external electric field. The resistivity is a function of the composite components, the volume fraction of each, the space dimension and a single morphology parameter. The McLachlan equation ${ }^{19}$ is used to build the model for predicting resistivity of a chosen electroconductive woven structure. On the basis of this model, a designer can influence the parameters of the structure to obtain a desired resistivity of composite. However, the resistivity of a material is a parameter that can be used in multiphysics simulation software to understand the physical phenomena of the designed textile object. ${ }^{20}$

\section{MATERIALS}

Electroconductive WF were chosen as research material. Raw material composition of the conductive plain-weave fabrics is as follows:

1. Nickel-plated polyester,

2. Tin + copper + silver-plated nylon,

3. Nickel + copper-plated nylon,

4. Silver-plated nylon,

5. Nickel-plated polyester.

Based on standard, ${ }^{21}$ sample thickness was determined. Based on standard, ${ }^{22}$ sample mass per unit area was determined. Number of warp and weft yarns was calculated using an Olympus SZX10 stereo microscope and stream motion software. Structure parameters of the WF are summarized in Table I.

Using an Olympus SZX10 stereo microscope and stream motion software, morphometric measurements of fabrics were also conducted. Images of WF were captured at total visual magnification of $9.45 \times$. Parameters of the fabric structure such as $d_{\text {wa }}$, the width of the warp yarns, $d_{\text {we }}$, the width of the weft yarns, $A_{\text {wa }}$, the spacing of the warp yarns, and $A_{\text {we }}$, the spacing of the weft yarns were designated (Fig. 1).

Measurements were performed in three areas of each sample. Received parameters of the WF are summarized in Table II. Moreover, variation coefficients $V d_{\text {wa }}, V d_{\text {we }}, V A_{\text {wa }}$, and $V A_{\text {we }}$, for $d_{\text {wa }}, d_{\text {we }}$, $A_{\text {wa }}$, and $A_{\text {we }}$, respectively, are given.
The variation coefficients of the parameters are in the range from $1 \%$ to $12 \%$ (Table II). The greater the value of variation coefficient, the greater is the irregularity of woven structure. Structures of WF are shown in Fig. 2.

\section{METHODS}

In order to describe the resistivity of a TCMC type of metal-dielectric, McLachlan's equation ${ }^{19}$ was assumed. The McLachlan equation was applied to the woven structure. ${ }^{23}$ Therefore, resistivity $\rho_{c}$ of WF can be expressed as

$$
\rho_{c}=\left(\frac{100}{C_{t}}\right)^{\frac{1}{1-L}} \rho_{m}
$$

where $\rho_{m}$ is the resistivity of the material, that is, the fabric without voids, $L$ is the depolarization factor, and $C_{t}$ is the percentage surface cover of the fabric by warp and weft yarns.

Resistivity of a rectangular or circular thin sample is given by the formula ${ }^{24}$ :

$$
\rho_{c}=\sqrt{\rho_{c 1} \rho_{c 2}}
$$

where $\rho_{c 1}$ and $\rho_{c 2}$ are the resistivities in directions $\mathrm{x}$ and y, respectively, as defined by Formula (1).

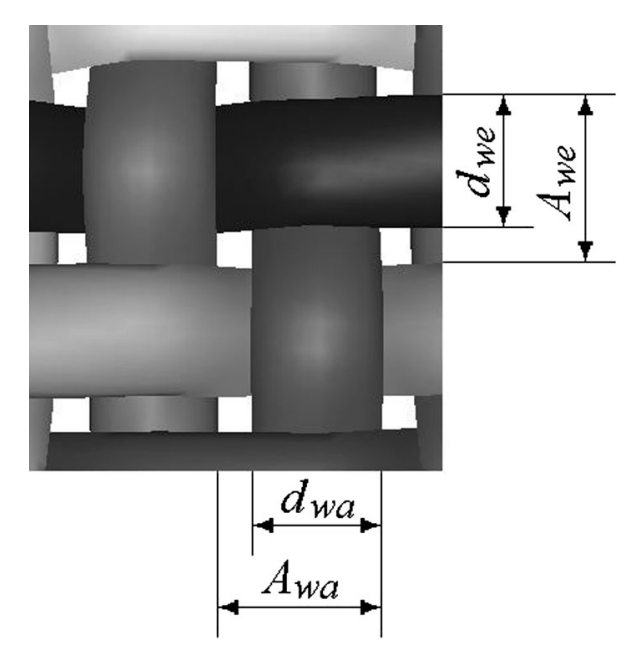

Fig. 1. Interlacing yarns in plain-weave fabric.

\begin{tabular}{|c|c|c|c|c|c|}
\hline Sample & $\begin{array}{l}\text { Thickness } \\
\text { (mm) }\end{array}$ & $\begin{array}{c}\text { Aerial } \\
\text { density } \\
\left(\mathbf{g} / \mathbf{m}^{2}\right)\end{array}$ & $\begin{array}{l}\text { Apparent } \\
\text { density } \\
\left(\mathbf{k g} / \mathbf{m}^{3}\right)\end{array}$ & $\begin{array}{c}\text { Warp density } \\
\text { (number of yarns } \\
\text { per } 1 \mathrm{~cm} \text { ) }\end{array}$ & $\begin{array}{c}\text { Weft density } \\
\text { (number of yarns } \\
\text { per } 1 \mathrm{~cm} \text { ) }\end{array}$ \\
\hline 1 & 0.078 & 75 & 962 & 28 & 20 \\
\hline 2 & 0.116 & 77 & 664 & 34 & 30 \\
\hline 3 & 0.176 & 96 & 545 & 37 & 29 \\
\hline 4 & 0.116 & 72 & 621 & 38 & 29 \\
\hline 5 & 0.188 & 65 & 346 & 20 & 13 \\
\hline
\end{tabular}

Table I. Structure parameters of electroconductive fabrics 
Table II. Results of morphometric measurements of fabrics

\begin{tabular}{|c|c|c|c|c|c|}
\hline Sample & 1 & 2 & 3 & 4 & 5 \\
\hline$d_{\mathrm{wa}}(\mathrm{mm})$ & 0.34 & 0.24 & 0.19 & 0.22 & 0.37 \\
\hline$V d_{\mathrm{wa}}(\%)$ & 3 & 2 & 5 & 3 & 7 \\
\hline$d_{\mathrm{we}}(\mathrm{mm})$ & 0.42 & 0.32 & 0.34 & 0.27 & 0.53 \\
\hline$V d_{\mathrm{we}}(\%)$ & 1 & 2 & 3 & 2 & 12 \\
\hline$A_{\text {wa }}(\mathrm{mm})$ & 0.36 & 0.29 & 0.27 & 0.26 & 0.50 \\
\hline$V A_{\mathrm{wa}}(\%)$ & 3 & 5 & 2 & 2 & 12 \\
\hline$A_{\text {we }}(\mathrm{mm})$ & 0.49 & 0.33 & 0.34 & 0.35 & 0.79 \\
\hline$V A_{\mathrm{we}}(\%)$ & 3 & 2 & 4 & 6 & 11 \\
\hline
\end{tabular}
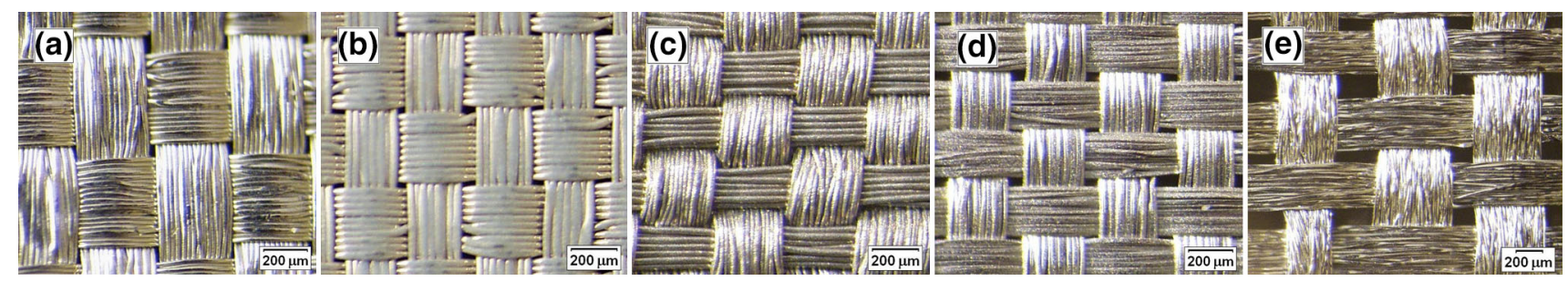

Fig. 2. Structures of WF (a) sample 1, (b) sample 2, (c) sample 3, (d) sample 4, (e) sample 5.

The percentage surface cover is expressed $\mathrm{as}^{23}$ :

$$
C_{t}=\frac{A_{\mathrm{we}} d_{\mathrm{wa}}+A_{\mathrm{wa}} d_{\mathrm{we}}-d_{\mathrm{wa}} d_{\mathrm{we}}}{A_{\mathrm{wa}} A_{\mathrm{we}}} 100
$$

where $d_{\mathrm{wa}}$ is the width of the warp yarns, $d_{\mathrm{we}}$ is the width of the weft yarns, $A_{\text {wa }}$ is the spacing of the warp yarns, and $A_{\text {we }}$ is the spacing of the weft yarns (see Fig. 1).

The depolarization factors for directions of the three principal axes, $x, y$, and $z$, and void-shaped anisotropic ellipsoids are given by ${ }^{25}$ :

$$
\begin{aligned}
L_{i} & =\frac{a_{1} a_{2} a_{3}}{2} \int_{0}^{\infty} \frac{\mathrm{d} s}{\left(s+a_{i}^{2}\right) \sqrt{\left(s+a_{1}^{2}\right)\left(s+a_{2}^{2}\right)\left(s+a_{3}^{2}\right)}} \\
i & =1,2,3
\end{aligned}
$$

where $a_{1}, a_{2}$, and $a_{3}$ are the semi-axes of the ellipsoid in directions $x, y$, and $z$, respectively, and $\sum_{i=1}^{3} L_{i}=1$.

In case of WF structure, the following dependences were adopted:

$$
\begin{gathered}
a_{1}=0.5\left(A_{\mathrm{wa}}-d_{\mathrm{wa}}\right) \\
a_{2}=0.5\left(A_{\mathrm{we}}-d_{\mathrm{we}}\right) \\
a_{3}=0.5 h
\end{gathered}
$$

where $h$ is the thickness of the fabric.

Based on Eqs. 1-4, the resistivity of the woven structure treated as TCMC is given by the formula

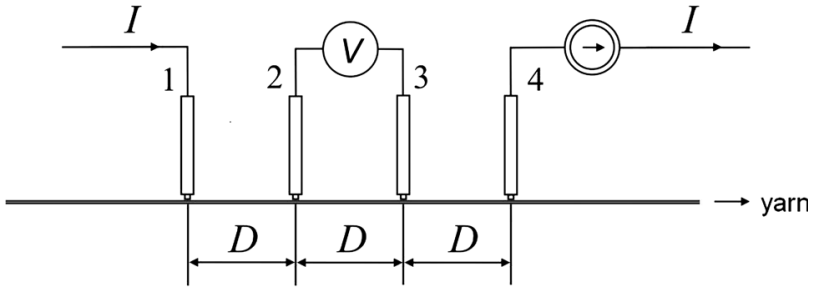

Fig. 3. Yarn resistivity measurements with four probes.

$$
\rho_{c}=\sqrt{\rho_{\mathrm{wa}} \rho_{\mathrm{we}}\left(\frac{100}{C_{t}}\right)^{\frac{2-L_{1}-L_{2}}{\left(L_{1}-1\right)\left(L_{2}-1\right)}}}
$$

where $\rho_{\mathrm{wa}}$ is the resistivity of the warp yarn and $\rho_{\mathrm{we}}$ is the resistivity of the weft yarn.

Resistivity $\rho_{\mathrm{wa}}$ and $\rho_{\mathrm{we}}$ of yarns can be determined using the four-probe method $^{26}$ and the following formula:

$$
\begin{gathered}
\rho_{\text {wa }}=\frac{R_{\text {wa }}}{D} s_{\text {wa }} \\
\rho_{\text {we }}=\frac{R_{\text {we }}}{D} s_{\text {we }}
\end{gathered}
$$

where $R_{\text {wa }}$ and $R_{\text {we }}$ are the resistances resulting from the quotient of the measured voltage drop between the two inner probes ( 2 and 3 ) and the current $I$ injected through the two outer probes ( 1 and 4) obtained for warp yarn and weft yarn, respectively (Fig. 3), $D$ is the voltage probe spacing, and $s_{\mathrm{wa}}$ and $s_{\mathrm{we}}$ are the cross section of warp yarn and weft yarn, respectively. 


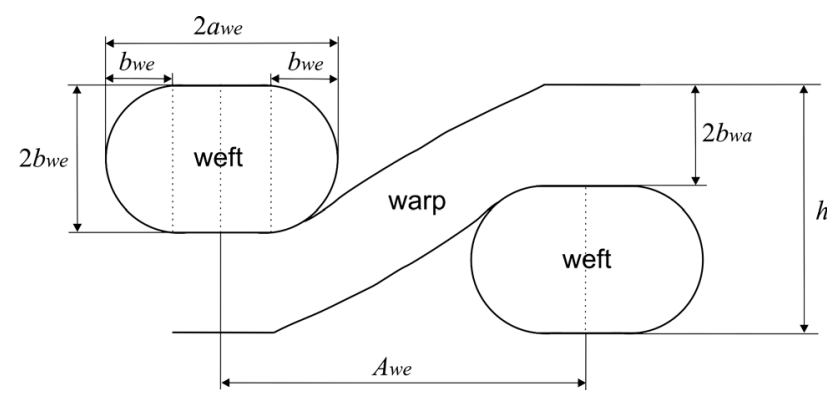

Fig. 4. Racetrack model.

The Kemp model of plain-weave fabric was assumed. ${ }^{27,28}$ Therefore, a racetrack geometry in a cross-section of the yarn was adopted (Fig. 4).

In Fig. 4, the cross-section of the weft yarns is presented, where $b_{\text {we }}$ and $b_{\text {wa }}$ are half of the shorter axis of the weft yarn and warp yarn, respectively; $a_{\mathrm{we}}$ and $a_{\mathrm{wa}}$ are half of the longer axis of the weft yarn and warp yarn, respectively; $a_{\mathrm{wa}}$ is invisible; $A_{\text {we }}$ and $A_{\text {wa }}$ are the spacing of the weft yarns and warp yarn, respectively; $A_{\text {wa }}$ is invisible; $h$ is the thickness of the fabric.

Based on the racetrack model, the cross-section of yarns, $s_{\text {wa }}$ and $s_{\text {we }}$, can be determined. Hence, Eqs. 9 and 10 take the form:

$$
\begin{gathered}
\rho_{\text {wa }}=\frac{R_{\text {wa }}}{D}\left[\pi\left(b_{\text {wa }}\right)^{2}+4 b_{\text {wa }}\left(a_{\text {wa }}-b_{\text {wa }}\right)\right] \\
\rho_{\text {we }}=\frac{R_{\text {we }}}{D}\left[\pi\left(b_{\text {we }}\right)^{2}+4 b_{\text {we }}\left(a_{\text {we }}-b_{\text {we }}\right)\right]
\end{gathered}
$$

wherein:

$$
\begin{aligned}
& a_{\mathrm{wa}}=0.5 d_{\mathrm{wa}} \\
& a_{\mathrm{we}}=0.5 d_{\mathrm{we}}
\end{aligned}
$$

where $d_{\text {wa }}$ and $d_{\text {we }}$ are the width of the warp yarns and weft yarns, respectively.

To determine the resistivity $\rho_{\mathrm{wa}}$ and $\rho_{\mathrm{we}}$ according to Eqs. 11 and 12, half of the shorter axis $b_{\text {wa }}$ and $b_{\text {we }}$ must be calculated. For this purpose, the following simultaneous equations were solved:

$$
\left\{\begin{array}{l}
\frac{\pi\left(d_{\mathrm{wa}}^{\prime}\right)^{2}}{4}=\pi\left(b_{\mathrm{wa}}\right)^{2}+4 b_{\mathrm{wa}}\left(a_{\mathrm{wa}}-b_{\mathrm{wa}}\right) \\
\frac{\pi\left(d_{\mathrm{we}}^{\prime}\right)^{2}}{4}=\pi\left(b_{\mathrm{we}}\right)^{2}+4 b_{\mathrm{we}}\left(a_{\mathrm{we}}-b_{\mathrm{we}}\right) \\
h=2 b_{\mathrm{wa}}+2 b_{\mathrm{we}} \\
d_{\mathrm{wa}}^{\prime}=d_{\mathrm{we}}^{\prime}
\end{array}\right.
$$

where $d_{\text {wa }}^{\prime}$ and $d_{\text {we }}^{\prime}$ are the diameter of the warp yarn and weft yarn, respectively, before the fabric was woven.

The area of the yarn cross-section before the fabric was woven from the yarns was circular shaped. The area is the same as in the case after the fabric was woven from the yarns with a

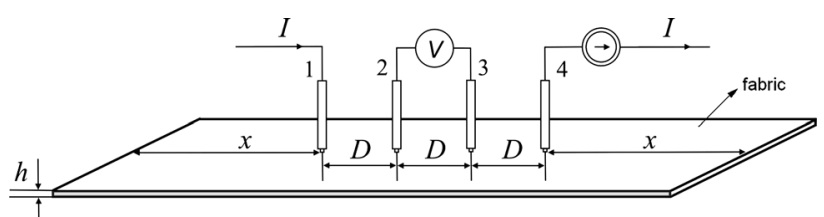

Fig. 5. Fabric resistivity measurements with four-point probes.

racetrack-shaped geometry. The diameters $d_{\text {wa }}^{\prime}$ and $d_{\text {we }}^{\prime}$ are equal because the chosen fabrics are made of the same yarns.

By solving the simultaneous Eq. 15, the diameters $d_{\text {wa }}^{\prime}$ and $d_{\text {we }}^{\prime}$ can also be calculated.

\section{Method of Verification}

The method of verification was based on comparison of the resistivity $\rho_{c}$ (8) and $\rho_{c}{ }^{*}$. The resistivity of WF, $\rho_{c}{ }^{*}$, can be determined using a four-point probe method $^{29}$ and the following formula:

$$
\rho_{c} *=C R h
$$

where $R$ - is the resistance resulting from the quotient of the measured voltage drop between the two inner probes ( 2 and 3 ) and the current $I$ injected through the two outer probes ( 1 and 4 ; Fig. 5 ), $C$ is the correction factor, and $h$ is the thickness of the fabric.

Dependence (16) is valid when $h<0.5 D$, where $D$ is the voltage probe spacing and $x>2 D$, where $x$ is the distance from the edge of thin square sample ${ }^{30}$ shown in Fig. 5.

The resistance $R$-(16) was calculated as an average of four resistances determined in four directions (Fig. 6). Angle $\varphi$ defines the direction in which the sample resistance was measured.

The factor $C$ can be found in Ref. 29 in the table of correction factors for the measurement of sheet resistivity with a four-point probe.

In order to assess the verification, the following indicator was proposed:

$$
v=\frac{\rho_{c}}{\rho_{c} *} 100 \%
$$

and denoted as the level of prediction in this paper. In the ideal case, $v=100 \%$.

\section{RESULTS}

Samples with an area in the shape of a $150-\mathrm{mm}$ sided square were prepared from electroconductive WF. Moreover, three warp yarns and three weft yarns of each fabric were prepared. All measurements were conducted under conditions described in standard. $^{31}$

In order to determine the resistivity $\rho_{c}(8)$, values of quantities such as $C_{t}, L_{1}$, and $L_{2}$ were calculated using dependences (3)-(7). The depolarization factor in the form of a complex number was received. Only the real part was taken into account because the 

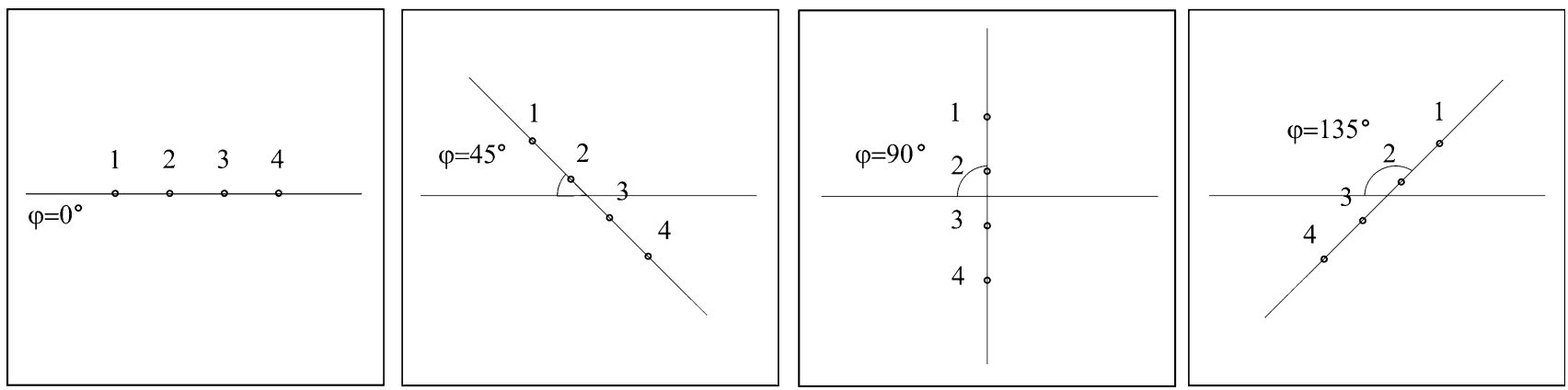

Fig. 6. Arrangement of probes in selected directions on sample surface.

Table III. Results of calculation

\begin{tabular}{|c|c|c|c|c|c|c|}
\hline Sample & $C_{t}(-)$ & $a_{1}(\mathrm{~mm})$ & $a_{2}(\mathrm{~mm})$ & $a_{3}(\mathrm{~mm})$ & $L_{1}(-)$ & $L_{2}(-)$ \\
\hline 1 & 99.1 & 0.010 & 0.038 & 0.039 & 0.695 & 0.155 \\
\hline 2 & 99.0 & 0.028 & 0.008 & 0.058 & 0.195 & 0.735 \\
\hline 3 & 99.7 & 0.042 & 0.002 & 0.088 & 0.041 & 0.946 \\
\hline 4 & 96.7 & 0.020 & 0.038 & 0.058 & 0.564 & 0.277 \\
\hline 5 & 91.7 & 0.065 & 0.127 & 0.094 & 0.475 & 0.213 \\
\hline
\end{tabular}

Table IV. Results of resistance measurements of warp and weft yarns

\begin{tabular}{|c|c|c|c|c|c|c|c|c|c|c|}
\hline \multirow[t]{3}{*}{ Sample } & \multicolumn{2}{|c|}{1} & \multicolumn{2}{|c|}{2} & \multicolumn{2}{|c|}{3} & \multicolumn{2}{|c|}{4} & \multicolumn{2}{|c|}{5} \\
\hline & $R_{\mathrm{wa}}(\Omega)$ & $R_{\text {we }}(\Omega)$ & $R_{\text {wa }}(\Omega)$ & $R_{\text {we }}(\Omega)$ & $R_{\text {wa }}(\Omega)$ & $R_{\mathrm{we}}(\Omega)$ & $R_{\text {wa }}(\Omega)$ & $R_{\text {we }}(\Omega)$ & $R_{\text {wa }}(\Omega)$ & $R_{\text {we }}(\Omega)$ \\
\hline & 21.74 & 19.39 & 1.99 & 1.20 & 4.61 & 2.47 & 2.86 & 2.48 & 6.42 & 2.94 \\
\hline$V(\%)$ & 6 & 5 & 5 & 2 & 4 & 4 & 2 & 5 & 2 & 4 \\
\hline
\end{tabular}

Table V. Results of calculation to determine the WF resistivity

\begin{tabular}{|c|c|c|c|c|c|c|c|c|}
\hline Sample & $a_{w a}(\mathbf{m m})$ & $a_{w e}(\mathbf{m m})$ & $b_{w a}(\mathbf{m m})$ & $b_{w e}(\mathbf{m m})$ & $d_{\text {wa }}^{\prime}=d_{\text {we }}(\mathrm{mm})$ & $\rho_{w a}(\Omega \mathrm{cm})$ & $\rho_{w e}(\Omega \mathrm{cm})$ & $\rho_{c}(\Omega \mathrm{cm})$ \\
\hline 1 & 0.170 & 0.210 & 0.0216 & 0.0174 & 0.1350 & $1.6 \cdot 10^{-3}$ & $1.4 \cdot 10^{-3}$ & $1.49 \cdot 10^{-3}$ \\
\hline 2 & 0.120 & 0.160 & 0.0335 & 0.0245 & 0.1388 & $1.5 \cdot 10^{-4}$ & $9.0 \cdot 10^{-5}$ & $1.18 \cdot 10^{-4}$ \\
\hline 3 & 0.095 & 0.170 & 0.0585 & 0.0295 & 0.1567 & $4.4 \cdot 10^{-4}$ & $4.2 \cdot 10^{-4}$ & $3.36 \cdot 10^{-4}$ \\
\hline 4 & 0.110 & 0.135 & 0.0323 & 0.0257 & 0.1302 & $1.9 \cdot 10^{-4}$ & $1.7 \cdot 10^{-4}$ & $1.92 \cdot 10^{-4}$ \\
\hline 5 & 0.185 & 0.265 & 0.0562 & 0.0378 & 0.2224 & $1.3 \cdot 10^{-3}$ & $5.7 \cdot 10^{-4}$ & $9.77 \cdot 10^{-4}$ \\
\hline
\end{tabular}

imaginary part, being of the order of magnitude $10^{-16}$ or less, can be treated as numerical error and neglected. Received results are presented in Table III.

Four cylindrical silver-plated brass probes were used to measure the yarn resistance. The contact diameter of the probe was equal to $2 \mathrm{~mm}$. The distance $D$ between voltage probes was equal to $20 \mathrm{~mm}$ (Fig. 3). A multimeter Agilent 34410A was used as a voltmeter and its resolution was $0.1 \mathrm{mV}$. A direct current (DC) power supply Agilent E3644A was used as an ammeter and its resolution was $1 \mathrm{~mA}$. Measurements of voltage drop for each yarn were repeated thrice. Received results and variation coefficient $V$ of resistance of warp/weft yarns are given in Table IV.

According to Eq. 15, the parameters of the racetrack model were calculated. Received results, resistivity of warp yarn $\rho_{w a}(11)$, resistivity of weft yarn $\rho_{w e}(12)$, and composite resistivity $\rho_{c}$ (8) are shown in Table V.

In order to verify the received results, resistance measurements of WF were conducted. The same four cylindrical brass silver-plated probes were used. The distance $x$ from the edge of the thin square sample was $44 \mathrm{~mm}$ (Fig. 5). It means that the measurement conditions specified for four-point probe method for measuring resistivity were fulfilled. A 
Table VI. Results of resistance measurements of WF

\begin{tabular}{|c|c|c|c|c|c|}
\hline Sample & 1 & 2 & 3 & 4 & 5 \\
\hline$R(\Omega)$ & 0.0557 & 0.0031 & 0.0054 & 0.0047 & 0.0502 \\
\hline$V_{\text {dir }}(\%)$ & 4 & 1 & 5 & 1 & 1 \\
\hline
\end{tabular}

Table VII. Results of verification

\begin{tabular}{|c|c|c|c|c|c|}
\hline Sample & 1 & 2 & 3 & 4 & 5 \\
\hline$\rho_{c}(\Omega \mathrm{cm})$ & $1.49 \cdot 10^{-3}$ & $1.18 \cdot 10^{-4}$ & $3.35 \cdot 10^{-4}$ & $1.92 \cdot 10^{-4}$ & $9.77 \cdot 10^{-4}$ \\
\hline$\rho_{c}^{*}(\Omega \mathrm{cm})$ & $1.74 \cdot 10^{-3}$ & $1.42 \cdot 10^{-4}$ & $3.82 \cdot 10^{-4}$ & $2.20 \cdot 10^{-4}$ & $3.79 \cdot 10^{-3}$ \\
\hline$v(\%)$ & 86 & 83 & 88 & 87 & 26 \\
\hline
\end{tabular}

multimeter Agilent 34410A was used as a voltmeter and its resolution was $0.001 \mathrm{mV}$. A DC power supply Agilent E3644A was used as an ammeter and its resolution was $1 \mathrm{~mA}$. Measurements of voltage drop were conducted in four directions (Fig. 6). Measurements were repeated six times. Variation coefficients of voltage in selected direction did not exceed $8 \%$. Values of average resistance are shown in Table VI. Moreover, the variation coefficient $V_{\text {dir }}$ of resistance in all directions is presented.

Next, according to Eq. 16, resistivity of WF, $\rho_{c}{ }^{*}$, was calculated. The factor $C$ was found in the table of correction factors. ${ }^{29}$ In the case of a thin sample with an area in the shape of a $150-\mathrm{mm}$-sided square and voltage probe spacing $D$ equals to $20 \mathrm{~mm}$, the factor $C$ is equal to 4.0095 . Results are shown in Table VII.

Moreover, the level of prediction $v$ (17) is also presented.

\section{DISCUSSION}

The flow of current in fabric takes place through both continuous elements (yarns) and the points of their contact. WF chosen for study were made of non-conductive material such as nylon or polyester. Fabrics were coated with thin adherent layers of nickel, tin, copper, or silver. In this way, high electric conductivity was obtained by the manufacturers. Therefore, we deal here with surface electrical conductivity of the fabric samples.

Electroconductive woven structure can be treated as TCMC that consists of conductive yarns and dielectric voids (empty spaces filled with air). The structure of the composite can be described using the percentage surface cover of the fabric by warp and weft yarns and parameters that describe the geometrical shape of voids. Shape and dimensions of voids in composite are measured by a depolarization factor.

Based on the indicator $C_{t}$, the percentage surface cover of the fabric by warp and weft yarns was determined. Values of $C_{t}$ increase from 91.7 to 99.7 (Table III). Thus, the percentage of voids in the fabrics is in the range of 0.3-8.3. Morphometric measurements of fabrics show the different degree of irregularity of woven structures. The variation coefficients of the received parameters are in the range from $1 \%$ to $12 \%$ (Table II).

Resistivity of warp yarn $\left(\rho_{\text {wa }}\right)$ and weft yarn $\left(\rho_{\text {we }}\right)$ are within the range of $1.5 \times 10^{-4} \Omega \mathrm{cm}$ to $1.6 \times 10^{-3} \Omega \mathrm{cm}$ and $9.0 \times 10^{-5} \Omega \mathrm{cm}$ to $1.4 \times$ $10^{-3} \Omega \mathrm{cm}$, respectively (Table V). Consequently, different resistivities of the warp and weft yarns was received though the same yarns $\left(d_{\text {wa }}=d_{\text {we }}\right)$ that were used to make the fabric. This is due to the different surface area of the yarns that were coated with a thin layer of metal.

Taking into account the resistivity of the yarns, fabric resistivity can be predicted based on the McLachlan Eq. 8. Resistivity of fabrics, $\rho_{c}$, is in the range of $1.18 \cdot 10^{-4} \Omega \mathrm{cm}$ to $1.49 \cdot 10^{-3} \Omega \mathrm{cm}$ (Table VII). In the case of samples $1-4$, verification is confirmed by the high level of prediction $v$ being in the range of $83-88 \%$.

In the case of sample 5 , the conducted verification was negative; and the level of prediction is only equal to $26 \%$. It allows one to pay attention to the following relevant factors in modeling the electroconductive properties of fabrics using the McLachlan equation. Percentage of voids in fabric is very important. A high percentage of voids affects the compactness and irregularity of the woven structure. Then, measurements of morphometric parameters of fabric structure are characterized by a large spread. One of the conditions described in stan$\operatorname{dard}^{32}$ is that the sample must not have any isolated holes. Using the chosen measurement method, all conditions must be fulfilled. In the case of sample 5 , the percentage surface cover $C_{t}=91.7 \%$ and morphometric measurement spreads are in the range of $7-12 \%$. Therefore, using the proposed model, attention should be paid to the compactness and irregularity of the WF structure.

On the other hand, by measuring the resistivity of the composite $\rho_{c}$, volume fraction of components, and voids dimensions and calculating the single 
morphology parameter in the form of depolarization factor, the resistivity of material $\rho_{m}$ can be estimated using the model described by Eq. 1.

\section{CONCLUSIONS}

The resistivity of electroconductive WF can be predicted based on the McLachlan equation. Using the model, a designer can influence the parameters of the structure to obtain a desired resistivity. The mathematical model based on the McLachlan equation is sensitive to compactness and irregularity of the woven structure. The proposed model is more appropriate than the resistive models that don't take into account the fabric structure but only the orientation of yarns. The resistivity of material can be also used in multiphysics simulation software to understand the physical phenomena of the designed textile object.

\section{CONFLICT OF INTEREST}

The author declares that there is no conflict of interest.

\section{OPEN ACCESS}

This article is distributed under the terms of the Creative Commons Attribution 4.0 International License (http://creativecommons.org/licenses/by/4.0/), which permits unrestricted use, distribution, and reproduction in any medium, provided you give appropriate credit to the original author(s) and the source, provide a link to the Creative Commons license, and indicate if changes were made.

\section{REFERENCES}

1. CEN/TR 16298:2011, Textiles and Textile Products. Smart Textiles. Definitions, Categorisation, Applications and Standardization needs.

2. L.M. Castano and A.B. Flatau, Smart Mater. Struct. 23, 1 (2014).

3. H.-Y. Song, J.-H. Lee, D. Kang, H. Cho, H.-S. Chuo, J.-W. Lee, and Y.-J. Lee, J. Text. Inst. 101, 758 (2010).

4. J. Leśnikowski and M. Tokarska, Text. Res. J. 84, 290 (2014).

5. I. Kazani, F. Declercq, M.L. Scarpello, C. Hertleer, H. Rogier, D. Vande Ginste, G. De Mey, G. Guxho, and L. Van Langenhove, Autex Res. J. 14, 47 (2014).
6. R.H. Guo, S.X. Jiang, C.W.M. Yuen, M.C.F. Ng, and J.W. Lan, J. Text. Inst. 104, 1049 (2013).

7. Z. Nakad, M. Jones, T. Martin, and R. Shenoy, Pervasive Mob. Comput. 3, 581 (2007).

8. J.-S. Roh, Text. Res. J. 84, 739 (2014).

9. Y. Lu, Q. Liang, and W. Li, Mater. Chem. Phys. 140, 553 (2013).

10. D. Depla, S. Segers, W. Leroy, T. Van Hove, and M. Van Parys, Text. Res. J. 81, 1808 (2011).

11. Z. Stempień, E. Rybicki, T. Rybicki, and J. Leśnikowski, Sens. Actuator B-Chem. 224, 714 (2016).

12. Y. Zhao, J. Tong, C. Yang, Y.-F. Chan, and L. Li, Text. Res. J. (2016). doi:10.1177/0040517515590408.

13. M. Tokarska, M. Frydrysiak, and J. Zięba, J. Mater. Sci.Mater. Electron. 24, 5061 (2013).

14. M. Neruda and L. Vojtech, J. Appl. Res. Technol. 10, 578 (2012).

15. S. Liu, J. Tong, C. Yang, and L. Li, Text. Res. J. (2016). doi: 10.1177/0040517516658509.

16. J. Wang, H. Long, S. Soltanian, P. Servati, and F. Ko, Text. Res. J. 84, 3 (2014).

17. M.L. Clingerman, Development and Modelling of Electrically Conductive Composite Materials. Doctoral thesis. Michigan Technological University, 2001).

18. D.S. McLachlan, J. Phys. C Solid State Phys. 19, 1339 (1986).

19. D. McLachlan, J. Phys. C Solid State Phys. 20, 865 (1987).

20. M. Ghahremani, M. Latifi, and M. Babaei, J. Ind. Text. (2016). doi:10.1177/1528083716632808.

21. ISO 5084:1996. Textiles-Determination of Thickness of Textiles and Textile Products.

22. ISO 3801:1977, Textiles-Woven Fabrics-Determination of Mass Per Unit Length and Mass Per Unit Area.

23. M. Tokarska, J. Mater. Sci.-Mater. Electron. 27, 7335 (2016).

24. J.D. Wasscher, Electrical Transport Phenomena in MnTe, an Antiferromagnetic Semiconductor (Eindhoven: Philips' Gloeilampenfabriken, 1969).

25. A.H. Sihvola and I.V. Lindell, AEU-Int. J. Electron. Commun. 50, 289 (1996).

26. BS EN 16812:2016. Textiles and Textile Products. Electrically Conductive Textiles. Determination of the Linear Electrical Resistance of Conductive Tracks.

27. A. Kemp, J. Text. Inst. Trans. 49, T44 (1958).

28. B.K. Behera, J. Militky, R. Mishra, and D. Kremenakova, in Woven Fabrics, ed. by H.-Y. Jeon (Rijeka, Croatia: InTech, 2012), pp. 1-32.

29. F.M. Smits, Bell Syst. Tech. J. 37, 711 (1958).

30. M.J. Deen and F. Pascal, J. Mater. Sci.-Mater. Electron. 17, 549 (2006).

31. ISO 139:2005, Textiles-Standard Atmospheres for Conditioning and Testing.

32. ASTM F76:2008, Standard Test Methods for Measuring Resistivity and Hall Coefficient and Determining Hall Mobility in Single-Crystal Semiconductors. 